\title{
Correction to: Multi-locus phylogenetic reconstructions reveal ample reticulate relationships among genera in Anthemideae subtribe Handeliinae (Compositae)
}

\author{
Christoph Oberprieler ${ }^{1}\left[\right.$ [ Hajar Hassanpour ${ }^{1,2} \cdot$ Ali Sonboli $^{3} \cdot$ Tankred Ott $^{1} \cdot$ Florian Wagner $^{1}$
}

Published online: 27 June 2019

(c) Springer-Verlag GmbH Austria, part of Springer Nature 2019

\section{Correction to: Plant Systematics and Evolution https://doi.org/10.1007/s00606-019-01588-0}

Unfortunately, the 3rd author affiliation was incorrectly published in the original publication.

The complete correct affiliation of Dr. Ali Sonboli is given below.

Medicinal Plants Research Institute, Shahid Beheshti University, Evin, 1983969411, Tehran, Iran.

Publisher's Note Springer Nature remains neutral with regard to jurisdictional claims in published maps and institutional affiliations.

The original article can be found online at https://doi.org/10.1007/ s00606-019-01588-0.

Christoph Oberprieler

christoph.oberprieler@ur.de

1 Evolutionary and Systematic Botany Group, Institute of Plant Sciences, University of Regensburg, Universitätsstr. 31, 93053 Regensburg, Germany

2 Department of Plant Biology, Faculty of Biological Sciences, Tarbiat Modares University, Tehran, Iran

3 Medicinal Plants Research Institute, Shahid Beheshti University, Evin, Tehran 1983969411, Iran 